\title{
Development of Foreign Language Education in China under the Belt and Road Initiative
}

\author{
Lihe Huang \\ Tongji University \\ Correspondence concerning this article should be addressed to Lihe Huang, Institute of Linguistics and \\ Multimodality, Tongji University, 1238 Gonghexin Rd, Zhongshan North Road, Zha Bei Qu, \\ Shanghai, China.E-mail: cranehlh@tongji.edu.cn
}

\begin{abstract}
China's launch of the Belt and Road Initiative (BRI) has had profound linguistic implications on its foreign language education policy. Successful foreign language programs are vital to any country's national security and global interest promotion. An analysis of China's current foreign language education with the BRI compliance will provide the backdrop for this paper's suggestions. The challenges and opportunities associated with the development of foreign language education in today's China will be analyzed under these four aspects: 1) improving in the variety and quality of foreign language education, 2) developing students' international and intercultural competence, 3) deepening general education in target languages, and 4) strengthening English as the lingua franca for expertise training. Even with the significant progress made thus far since 40 years of "Reform and Opening-up", China still has a long way to go in developing its national foreign language capacity to serve its expanding national interests for development.
\end{abstract}

Keywords: Belt and Road Initiative; foreign language education; national interests; language policy; China's development

\section{Introduction}

The launch of the Belt and Road Initiative (BRI) ${ }^{1}$ reflects a new shift in the role China plays in the international arena. With an ever-increasing global interest, China is expanding its foreign language resources to facilitate regional expertise, multilateral exchanges, and global governance. Under this background, there is great demand and intense international competition for quality talent with foreign language ability and regional expertise, who "are imbued with global vision, well-versed in international rules" ${ }^{2}$, in the fields of economics and finance, science and technology, and education and culture.

Spanning three continents, Asia, Europe, and Africa, the Belt and Road connects 65 countries and 4.4 billion people, or $63 \%$ of the world's population, including over 50 different official languages. Since economic cooperation and cultural exchange are largely based on efficient communication utilizing their native languages, foreign languages play an integral and significant role in the implementation of the BRI.

However, a quick observation of the current state of affairs of foreign language education in China reveals a shortage of strategically-important languages being taught. This is particularly true with Belt and Road languages. Several years ago, from 2010 to 2013, only about 20 official languages in the Belt and Road region were available for college students nationwide. Among these 20 foreign language departments, there remain significant problems such as the small recruitment scope, an unbalanced male-female ratio, and an undiversified curriculum (Wen, 2015). Therefore, the current linguistic service that China can provide remains severely inadequate for the pragmatic demand of the BRI's implementation. Under such a background, this paper hopes to shed new light on what the BRI brings to foreign language education and how this national interest directive should guide future development on the belief that foreign language education is an indispensable part of the Initiative's realization.

\footnotetext{
1 For the definition of the BRI, please see: http://www.china.org.cn/english/china_key_words/2019-04/17/content_74691589.htm

2 Outline of China's National Plan for Medium and Long-term Education Reform and Development (2010-2020)
} 


\section{What does the BRI Mean to Foreign Language Education?}

The BRI represents a profound transformation of national interest strategy and is an essential step in China's increased proactive participation in regional and global governance and development. This Initiative sets forth several cooperation priorities, including policy coordination, facilities connectivity, unimpeded trade, financial integration, and people-to-people bonding. To achieve these goals, the countries along the Belt and Road are supposed to be actively involved in a wide range of areas, such as infrastructure connectivity, industrial investment, resource development, economic (trade) cooperation, financial cooperation, cultural exchanges, environmental protection, and maritime cooperation. To a large extent, linguistic competence, cultural respect, and mutual understanding presented by those who are engaged in these areas will facilitate the activities. In other words, "language" under the implementation of the BRI not only works as the prominent communicative tool but also provides the basis for regional studies and cultural development, at the same time fulfilling China's national interests and development needs.

Generally speaking, political philosophy and national interests inevitably determine a country's policy-making, including foreign language planning. China primarily "weighs its foreign language need with its international exchange activities, with particular reference to its economic, political, and cultural exchange activities with foreign countries in the global arena" (Gong \& Guo, 2019: 28). In other words, the scope and quality of foreign languages available in China should provide significant and vital support for the country to launch a series of economic initiatives, to promote more people-to-people exchanges, and deepen strategic ties with the countries along the Belt and Road. In this sense, foreign language education in China should be considered from the perspective of its national strategy and thus regarded as an essential factor for China's continued global rise.

Such consideration comes from the acknowledgment that foreign languages are a valuable resource for a nation. Ruíz (1983) claims that the basic orientation or attitude that governments have toward language and its role in society influence the nature of language planning efforts in practice. He proposes three orientations: languageas-a-problem, language-as-a-right, and language-as-a-resource. Most countries focused their attention on the first two aspects in the early days of their language planning. Using China as an example, in the 1950s, the government implemented simplified Chinese written characters and Pinyin systems. The government also provided rights-affirmation with the legalization of mother language usage among all ethnic minorities living within the country. These attempts reflect China's orientation of language-as-a-problem and language-as-aright toward its role in the process of national modernization.

Therefore, with its further comprehensive development and expanding interest, China has gradually paid particular attention to the idea of recognizing language-as-a-resource. Scholars and administrators began to realize the scope and quality of foreign languages available in China can provide significant and vital support for the country to launch a series of global or regional initiatives, to promote more people-to-people exchanges, and thus deepen strategic ties with the countries along the Belt and Road.

\section{Developing National Foreign Language Capacity: Definition and Experience}

With an increasing need for communication and collaboration in today's global affairs, any country that aims to shoulder more international responsibility or raise its global impact must expand its international executive ability. Without a doubt, national foreign language capacity is a foundation for such an ability. This section discusses the definition of national foreign language capacity and the experience of some countries.

National language capacity refers to "the total of a nation's ability to grasp linguistic resources, provide language services, deal with linguistic issues, develop the language, and related tasks". A nation's language capacity is both a function of its hard and soft power, and plays a critical role in "social progress and cultural inheritance, in promoting economic development and technological innovation, and in protecting a country's national security and international development" (Zhao, 2016).

As part of national language capacity, foreign language capacity is considered to be closely related to the problems of national security and the global interest of a country. Wen, Su \& Jian (2011:4-5) refer to national foreign language capacity as "a nation's ability to cope with various language events." The fundamental standard to measure a nation's foreign language capacity is the type and quality of foreign language resources in that nation. Therefore, foreign language education serves as the primary vehicle to satisfy this need. 


\section{LIHE HUANG}

We can see this point from the examples of some most geographically important countries' practices (USA, Russia, and France $)^{3}$, which interpret the significance of developing foreign language education as an integral part of their national security and global interest policies.

In the USA, after the September $11^{\text {th }}$ terrorist attacks, the government increasingly realized the importance of foreign languages in maintaining its national security (DeCamp et al., 2012). At that time, several members of Congress initiated bills to promote foreign language education for the sake of national interest and security, including the National Security Language Act by Rush D. Holt and the National Foreign Language Coordination Act by Daniel Akaka and other senators. After a series of proposed bills and conferences, President George W. Bush officially released the National Security Language Initiative in 2006. In addition to overall national language capacity, the US government also attaches great importance to foreign language capability in the military to improve its security and global mobility. The National Security Education Program ${ }^{4}$ and two other documents (Defense Language Transformation Roadmap and DoD Strategic Plan for Language Skills, Regional Expertise, and Cultural Capabilities: 2011-2016) that are released by the Department of Defense systematically reflect the thought and practice of foreign language strategy in the military sector. ${ }^{5}$ In brief, a series of measures have been taken to ensure that the US Army obtains a rather strong foreign language capacity in terms of the number of languages and the management of its abundant foreign language resources.

In Russia, the most esteemed universities, including Saint-Petersburg State University, Lomonosov Moscow State University, and Moscow State Institute of International Relations, maintain a wide variety of high-quality foreign language resources, and the government also makes a concerted effort to improve the foreign language capacity of its military (Li, 2014).

Similarly, in France, INALCO (Institut national des langues et civilisations orientales) currently offers programs in approximately 100 languages and cultures, which endow the nation with extensive foreign language capacity and equips it with the ability to tackle international affairs and events through the employment of foreign languages (Dai, 2014).

These countries fully recognize the importance of rich and vibrant foreign language resources since that is what largely determines a nation's capacity to gather and analyze intelligence, covert communication, and military coordination in the international community. China, however, as the second-largest global economic contributor, has a wide gap when compared with the other large economies in the world in terms of foreign language capacity. With the ever-expanding demand for global cooperation in today's world, China needs to systematically improve its foreign language capacity to match its historically-changing mission, as a regional power with immense global influence.

\section{How to Respond: Foreign Language Education Reform in China}

Language education policy focuses on "what languages are desirable in the repertoire of speakers in the community and for what purposes those languages will be used" (Kaplan \& Baldauf, 1997: 126). In the context of the BRI, the purpose of the language education policy is to enhance China's foreign language capacity and promote the implementation of the Initiative. With more people voicing their concerns regarding the reform of foreign language education in China, the government began to consider some specific and practical approaches to improve China's national foreign language capacity. This section offers our suggestions on how to improve it through a scientific and practical top-down design of foreign language education in the sector of Chinese higher education.

Under the BRI, we will consider the development of foreign language education from the four aspects explained below.

\footnotetext{
3 The USA is a global power without a doubt. Both Russia and France are important powers in Eurasia, producing massive influence on global affairs. The analysis of these three countries can provide evidence of how national foreign language capacity is built.

4 National Security Education Program, National Defense University \& Department of Defense. (2003). United States Civilian Linguist Reserve Corps Feasibility Study.Available at https://nsep.gov/docs/CivilianLinguistReserveCorpsFeasibilityStudy.pdf

5 GAO. (2011). Military training: Actions needed to improve planning and coordination of Army and Marine Corps language and culture training. Retrieved from https://www.gao.gov/assets/320/318899.pdf
} 


\section{Improve the Variety and Quality of Foreign Language Education}

If we observe the higher education community in China as a whole, English ranks at the top as the first foreign language for most institutions. This country has the most significant number of students in the world who are learning English through formal instruction (Wen, 2012). Numerous institutions or departments of "foreign languages" consist of English and one or more of several other languages. Most of these other foreign languages are relatively common-usage languages, such as French, Japanese, German, or Spanish. Other more exotic foreign languages, including those strategically and geopolitically crucial for dealing with Belt and Road countries but minor in terms of the speaking population, can be found in only a relatively small number of settings. Even in these professional institutes or colleges, the total number of foreign languages accessible to students is still quite small. The three most esteemed professional institutions for foreign language talent cultivation in China provide a relatively limited number of foreign language courses when compared to their counterparts in the USA or Russia. According to the homepage introduction of these three leading foreign language education institutions, Beijing Foreign Studies University ${ }^{6}$ provides 98 foreign language courses currently, Shanghai International Studies University ${ }^{7} 42$, and Guangdong University of Foreign Studies ${ }^{8} 26$.

An indigent foreign language resource in this nation will impede national security maintenance and globalinterest exploration. A country seeking more proactive participation in global affairs needs to hold rich foreign language resources. For example, the USA and Russia rank their "critical languages" in terms of the security requirement and their national interest. Considering the engagement of foreign languages with national interest and security, the government should realize that the market demands could not regulate the design of foreign language education. As an emerging country that bears increasing responsibility in global governance, China should also plan for and designate some foreign languages as "critical languages" and effectively promote the acquisition of these languages among its students.

Fortunately, as a response to the need to extend the variety of foreign languages, major foreign language institutes and universities have already launched their plans. Beijing Foreign Studies University, for example, pledged to establish over one hundred language departments before 2020, which will cover all the languages used by the countries that have diplomatic ties with China. Shanghai International Studies University plans to add another ten foreign language departments or courses within three years, all responding to languages used by Belt and Road countries.

\section{Develop Students' Intercultural Competence and International Experience}

In today's higher education sector, a consensus has been reached that intercultural competence training plays an essential role in the successful practice of foreign language education (Borjian, 2014).

As the world's largest developing country and a permanent member of the UN Security Council, China plays an active role as a participant, defender, and reformer of the contemporary international order in the United Nations. However, the current number of Chinese staff in the UN is only 546 , or $1.46 \%$ of total UN staff, which is below the "desirable range" assigned by the UN. Conversely, the staff from the USA comprises 2531, or 6.75\% of all UN staff. ${ }^{9}$ Additionally, the number of senior Chinese officials in international organizations remains disproportionately small. The small number and low proportion of Chinese staff in the UN do not conform with the international status reflected by China's contributions in today's world. This disparity will undermine China's global discourse power, its power in drafting and revising international regulations, and the expansion of its global interests.

High-level foreign language talent is always required in the competitive fields of trade, finance, education, science, and technology. There is, therefore, a strong need for foreign language and regional research talent that is committed to high-level academic endeavors, is imbued with multilingual competence, has a global vision, and can actively participate and compete on an international level. Undoubtedly, foreign language education serves as an indispensable channel to cultivate these talents (Hunter, White \& Godbey 2006; Dai \& Wang, 2015:3).

\footnotetext{
6 http://www.bfsu.edu.cn/overview

7 http://www.shisu.edu.cn/about/introducing-sisu

http://www.gdufs.edu.cn/About\%20GDUFS/General\%20Information.htm

9 Composition of the Secretariat: staff demographics, 22 April 2019. Document No. A/74/82.
} 
For those non-foreign language majors at Chinese universities, some intercultural courses given in English have been accessible to them, mostly in the form of College English Teaching. Shu (2013) believes that English teaching should foster students' intercultural competence, meet the need for the internationalization of Chinese higher education, and eventually serve China's national interest in the further opening to the outside world. So, for these students, the English courses help develop intercultural competence and familiarize them with international conventions. Additionally, the organization of intercultural activities on campus is also an important key to developing students' intercultural competence (Huang, 2015; 2017). Different sorts of activities target different dimensions of intercultural competence. These goals include: improving students' intercultural awareness and equipping them with basic intercultural/international knowledge, developing their capacity to reflect and think from an intercultural perspective, and providing opportunities to interact with people from around the world. To put this idea into practice, Huang (2017) developed a four-module system for a co-curricular activitybased intercultural competence training program and offers suggestions for its implementation. Under such a system, a pedagogical design is introduced for intercultural education using the BRI theme to help students in developing and assessing their intercultural competence. It is believed that this pedagogical design and its practice are feasible and accessible to students in both the Chinese setting and the international arena (Huang, 2018).

\section{Deepen General Education for Target Languages}

General education is not new in China. These courses cover a wide and diverse range of disciplines and fields, which are usually accessible to all the students at the university. However, tradition holds that these courses are usually taught in Chinese, even at the top universities. In recent years, some universities in China, in an effort to pursue internationalization at home, began to initiate general education courses in foreign languages (basically in English). For example, during the past several years, Tongji University has provided a series of general education courses given in several foreign languages, such as the English/German ${ }^{10}$-taught courses entitled "China Today" ${ }^{11}$, which are accessible for both Chinese students and international students in the university. These English/German-taught courses focus on a general introduction to China from both diachronic and synchronic perspectives in a global context. According to the syllabi, the students are supposed to develop an overall understanding of China's history, culture, society, economy, foreign relations, environmental protection, urban development, and intellectual property, etc. The aim is to equip students with reasonable points of view on China's rise, while supporting more proactive participation in global governance. The courses should lead students to more comprehensive education on Chinese traditional values and updated spirit. Obviously, the teaching builds bridges across different disciplines in students' knowledge development, which is a trend in today's universities' internationalization (Schechter, 1993).

Meanwhile, through these courses, students are trained to view global development and China's wisdom critically, and further "tell a good story" of China in English or German to the international community by adopting an international discourse system. Undoubtedly, this attempt is helpful for introducing the experience of contemporary China's prosperity and peaceful rise, and share the wisdom of China's contributions to world development.

Inspired by the practice at Tongji University, we suggest that foreign language institutions and other universities establish courses taught in foreign languages in fields that focus on contemporary China and the world, especially humanities and social science. These general education courses with foreign language mediation will help to train foreign language majors and other students with the capacity of bridging China with the world. This provides an indispensable level of competence for the youth and future of China to improve China's national image in the global arena.

\section{Strengthen English as the Lingua Franca in Expertise Training}

From the perspective of national foreign language capacity, teaching each of the languages spoken in the Belt and Road countries is a worthy goal. Multilingualism, after all, leads to a more diversified world and promotes intercultural communication. However, the status quo of English as a lingua franca and its dominant prevalence

\footnotetext{
10 The history of Tongji University can be traced back to 1907, when the German Medical School was founded by Erich Paulun, a German doctor. Therefore, German teaching is a tradition that has existed for the last century.

11 The courses package includes: Intercultural Communication, Multiculturalism and Global Governance, Chinese History and Culture, China's Foreign Affairs and International Relations, China's Socio-Economic Development, Shape and Growth of the Town \& Village in China, Cultural Heritage Conservation in China, Sustainable Development in China, Chinese Intellectual Property Protection, Urban Culture and Urban Aesthetics, and Chinese Music and Songs.
} 
in the international community are irrefutable facts (Huang, 2017: 185). This produces a problem of how to motivate students to learn other foreign languages in addition to English.

To solve this problem, educators should find a feasible way to initiate more robust foreign language programs that focus on common foreign languages, including English. Practically, a competent international talent should be equipped with a good command of two and more foreign languages (one of which should be English) and non-linguistic-based expertise in a specific field of study. Excellent language proficiency by itself will not lead to an adequate capacity for meaningful participation in international cooperation and competition. In this sense, to cultivate "compound talents" in foreign language departments must be advocated in China. "Compound" here means students should acquire enough professional knowledge and skills in specific fields in addition to their excellent proficiency in foreign languages. The expertise knowledge could exist in fields such as business, economics, finance, law, management, diplomacy, or international relations.

For example, some foreign language institutions in China practice the idea that the curriculum should combine language skill development with regional expertise. In the courses developing regional expertise, special attention should be paid to certain disciplinary knowledge training, especially in political science, economics, law, anthropology, and linguistics. Meanwhile, others attach greater importance to developing students' skills of other foreign languages in addition to English, French, or the other commonly spoken languages in the international community. Therefore, "English + less-commonly spoken foreign language + certain expertise" or "English + two or three less-commonly spoken foreign languages" are the frequent models adopted by these institutions. Expertise training, together with foreign language education, will improve students' career competence and provide a practical basis for their motivation and willingness to learn other less-attractive languages spoken by the Belt and Road countries.

Based on the previous discussion, the roadmap for strengthening China's foreign language capacity is illustrated as follows:

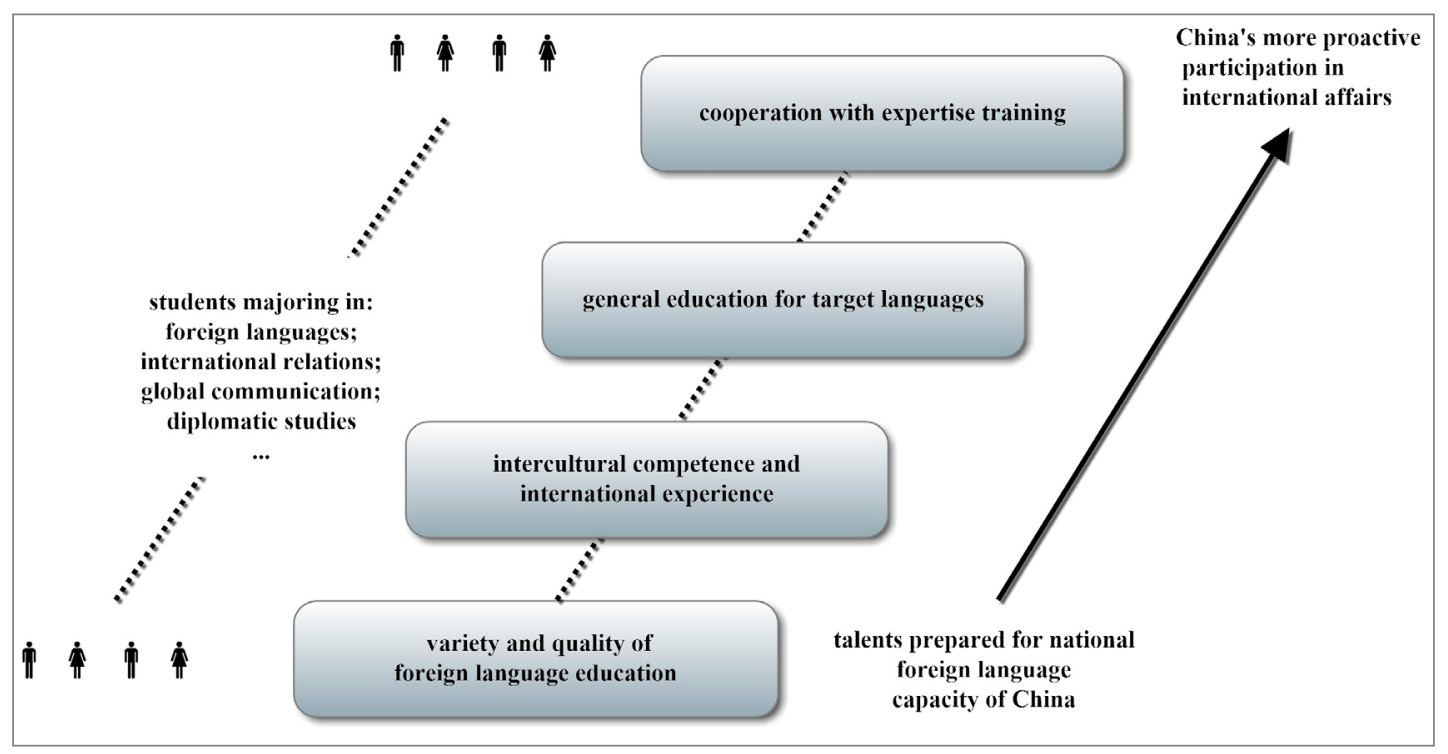

Diagram 1. A Roadmap to Strengthen China's Foreign Language Capacity through Foreign Language Education.

This roadmap also presents the necessary components that are needed for China's proactive participation in international affairs, cooperation, and competition from the perspective of foreign language talent development.

\section{Conclusion}

China's rapid rise and its proactive participation in global governance have led the country to pursue more world-connected national interests and shoulder more international responsibilities, which breeds the implementation of the BRI. A project of this magnitude reminded Chinese educators in the foreign language sector of the necessity and urgency of improving the nation's foreign language capacity for the sake of national 


\section{LIHE HUANG}

interest. This task, ultimately, lies in the reform of foreign language education and the cultivation of highquality talents. Fortunately, an increasing number of scholars in China have helped the government move on to this task (Zhao \& Huang, 2016).

From the previous discussion, we can see that foreign language education in China is not just a simple issue of teaching. Instead, it bears immense responsibility for maintaining China's national interest in the global era in which China is playing an increasingly important role. Therefore, it can be understood why foreign language education matters so much in the implementation of the BRI and China's further involvement in international affairs.

At the current stage, the Chinese government should initiate a complete redesign of foreign language education, and set up a specific institution or administrative mechanism to coordinate national foreign language education (Li, 2010), which is to plan, practice and evaluate the teaching for all relevant institutions. In the USA, the counterpart organization would be the National Foreign Language Center, which is an institution claiming "to improve the capacity of the U.S. to communicate in languages other than English."12

Although some Chinese scholars claim that "the number and scale of non-English foreign language degree programs in Chinese universities have been growing dramatically" (Han, Gao \& Xia, 2019: 5), the exact foreign language needs in China should be evaluated systemically in light of the economic, political, and cultural exchange needs in the BRI (Gong \& Guo, 2019). Based on scientific planning needed for foreign language education, more foreign language talents should be cultivated, including high-quality translators or interpreters, staff in international organizations, business and law talents with excellent command of foreign languages, etc. These human resources will facilitate exchanges and cooperation among the countries or regions along the Belt and Road regions, and further promote China's participation in global affairs, or at least "tell a better story" to help the international community understand China's rise and hopefully reduce any misunderstandings or perceived hostilities.

Although there is "a significant leap in the growth of non-English foreign language programs in Chinese universities, many of these programs need to address a variety of challenges including 'unrealistic' curriculum objectives, teacher shortages, and attracting high-quality applicants" (Han, Gao \& Xia, 2019). China has been an emerging economic and political power in the world after 40 years of "Reform and Opening-up". Nevertheless, this country still has a long way to go in developing its competitive national foreign language capacity. Even so, China's development, of course, will provide valuable experience for other emerging economies to more actively participate in global affairs and seek their own interests.

\section{Acknowledgment}

This paper and its related work have been supported by the following grants: China Language Assessment Project (2018) "A Study of International Competence and Its Assessment for Chinese Students"(No.ZGWYCPJJ2018015B); Tongii University Teaching Reform Project (2019-2020) "Core Lessons Construction of Global Insight and Critical Thinking for English Majors in the Framework of General Education” (No. 1100104108/003); Tongji University Interdisciplinary Course Construction Grant “Multiculturalism and Global Governance” (No. 1100104113).

\section{References}

Borjian, Maryam. (2014). Language-education policies and international institutions: The World Bank's vs. UNESCO's global framework. Language Problems \& Language Planning, 38(1), 1-18.

Dai, D. (2014). France's national language capacity building: The case of INALCO. Foreign Language Education in China, 7(4), 3-9.

Dai, W., \& Wang, X. (2015). The developmental strategies of the discipline of foreign languages and literature under the background of Chinese cultural diffusion. Journal of PLA University of Foreign Languages, 38(4), $1-11$.

${ }^{12} \mathrm{http} / / /$ www.nflc.umd.edu/mission 
DeCamp, J., Meadows. S. O., Costa, B., Williams, K. M., Barnmann, J., \& Overton, M. (2012). An assessment of the ability of the U.S. Department of Defense and the Services to measure and track language and culture training and capabilities among general purpose forces. Santa Monica, CA: RAND Corporation.

Gong, T., \& Guo, Y. (2019). A critical review of China's foreign language program development: The perspective of language needs. Círculo De Lingüística Aplicada a La Comunicación, 79, 21-44. https://doi.org/10.5209/clac.65646

Han, Ya., Gao, X., \& Xia, J. (2019). Problematising recent developments in non-English foreign language education in Chinese universities, Journal of Multilingual and Multicultural Development, 40(7), 562-575. https://doi.org/10.1080/01434632.2019.1571072

Huang, L. (2015). Improving intercultural education at Chinese institutions from German experience. Journal of International Students, 5(3), 201-203.

Huang, L. (2017). Co-curricular activity-based intercultural competence development: Students' outcome of internationalization at universities. Innovations in Education and Teaching International, 54(3), 184-193. https://doi.org/10.1080/14703297.2016.1184098

Huang, L. (2018). Intercultural education on the theme of the belt \& road initiative: A pedagogical design. In Yu Cheng, L. Song \& L. Huang (Eds.), The belt and road to a better future: China-Europe youth dialogue (pp. 35-54.). New York, NY: Routledge.

Hunter, B., White G.P. , \& Godbey G.C. (2006). What does it mean to be globally competent? Journal of Studies in Higher Education, 10(3), 67-285.

Kaplan, R. B., \& Baldauf, R. B., Jr. (1997). Language planning from practice to theory. Clevedon, UK: Multilingual Matters.

$\mathrm{Li}$, Yu. (2010). Some thoughts on foreign language planning in China. Journal of Foreign Languages, 33(1), 2-8.

Li, Yi. (2014). A study of Russian universities improving national foreign language capacity. Journal of Tianjin Foreign Studies University, 21(2), 49-54.

Ruíz, R. (1983). Orientations in language planning. Bilingual Research Journal, 8(2), 15-34.

Schechter, M. G. (1993). Internationalizing the university and building bridges across disciplines. In S. T. Cavusgil (Ed.), Internationalizing Business Education (pp. 129-140). East Lansing, MC: Michigan State University Press.

Wen, Qi. (2015). The urgent need to develop the strategic plan on the talents cultivation of less-commonly taught foreign languages for the belt and road initiative. In Collection of the Project Outcomes of the National Social Science Fund of China, 1037(96). Beijing, China: Xuexi Publishing House.

Wen, Qi., Su, J., \& Jiang Ya. (2011). A model of national foreign language capacity and its trial use. Foreign Languages in China, 8(3), 4-10.

Wen, Qi. (2012). Teaching English as an international language in mainland China. In A. Kirkpatrick \& R. Sussex Roland (Eds.), English as an international language in Asia: Implications for language education. New York, NY: Springer.

Zhao, Sh. (2016). National language capacity in global competition. Social Sciences in China, 37(3), 93-110. https://doi.org/10.1080/02529203.2016.1194633

Zhao, Sh., \& Huang, N. (2016). (Eds.) Language service and One Belt and One Road. Beijing, China: Social Science Academic Press. 